ALLEGORICAL IMAGERY 



\section{$A \mathbb{L} \mathbb{L} \mathbb{E} G O \mathbb{R} I \mathbb{C} A \mathbb{L}$}

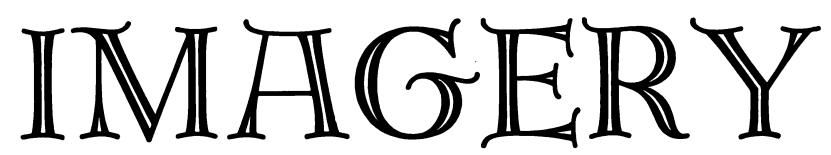

Some Mediaeval Books and $\tau_{\text {beir }} \mathfrak{Y o s t e r i t y}$

BY ROSEMOND TUVE

1966

PRINCETON UNIVERSITY PRESS

PRINCETON, NEW JERSEY 
Copyright (C) 1966 by Princeton University Press ALL RIGHTS RESERVED

L.C. Card 65-14312

ISBN: 978-0-6916-5639-7 ISBN: 978-0-6916-1638-4

Princeton Legacy Library edition 2019 Paperback ISBN: 978-0-691-61638-4 Hardcover ISBN: 978-0-691-65639-7 